\title{
The Use of Design-science to Define Information Content Requirements for IT Service
} Catalogs

\author{
Schorr, Franziska; Hvam, Lars
}

Published in:

2018 IEEE International Conference on Industrial Engineering and Engineering Management (IEEM)

Link to article, DOI:

10.1109/IEEM.2018.8607318

Publication date:

2019

Document Version

Peer reviewed version

Link back to DTU Orbit

Citation (APA):

Schorr, F., \& Hvam, L. (2019). The Use of Design-science to Define Information Content Requirements for IT Service Catalogs. In 2018 IEEE International Conference on Industrial Engineering and Engineering Management (IEEM) (pp. 497-501). IEEE. https://doi.org/10.1109/IEEM.2018.8607318

\section{General rights}

Copyright and moral rights for the publications made accessible in the public portal are retained by the authors and/or other copyright owners and it is a condition of accessing publications that users recognise and abide by the legal requirements associated with these rights.

- Users may download and print one copy of any publication from the public portal for the purpose of private study or research.

- You may not further distribute the material or use it for any profit-making activity or commercial gain

- You may freely distribute the URL identifying the publication in the public portal 


\title{
The Use of Design-science to Define Information Content Requirements for IT Service Catalogs
}

\author{
F. Schorr ${ }^{1}$, L. Hvam ${ }^{1}$ \\ ${ }^{1}$ Department of Management Engineering, Technical University of Denmark, Kongens Lyngby, Denmark \\ (frsc@dtu.dk, lahv@dtu.dk)
}

\begin{abstract}
An information technology (IT) service catalog is a knowledge management system that provides information about IT services to both customers and service providers. When designing and implementing an IT service catalog as part of the IT service management, firms often struggle with defining the scope of the information content required for such a knowledge management system. Whereas information is an expensive resource, scholars did not determine how the information content of an IT service catalog can be determined to fit the expected use of the service catalog. This study explores the use of design science methods to define and evaluate requirements for the information content of IT service catalogs. The use of this method in the early stage of the IT service catalog design process led to a justification of design objectives and a proactive reduction of the scope of the IT service catalog.
\end{abstract}

Keywords - IT service, IT service management, IT service catalog, design science research, ITIL, knowledge management capability

\section{INTRODUCTION}

IT departments are making a strategy shift from being technology managers for business's needs to becoming key business partners. Often, service-oriented IT departments offer typical IT products, such as hardware and software, not as stand-alone products but instead delivered as services. Delivering IT products as services includes, e.g., running and supporting the IT products over its lifecycle. Especially in the service industry, IT departments are thus becoming active value creators for the business, with firms actively managing IT departments.

Documenting offered IT services regarding its business value and technical requirements is a fundamental prerequisite for IT service management. The use of IT has grown over the years and IT departments may not yet have a clear picture of what services they are providing. From missing documentation comes business's lack of understanding of how IT departments create value to customers. To understand resource requirements and cost of IT services, IT managers must know the explicit technical requirements for delivering an IT service. Therefore, IT departments have to outline their service offerings to move the IT operations from a technologymanagement to a service provider approach.

The Information Technology Infrastructure Library standard (ITIL) proposes to implement an IT service catalog [1]. An IT service catalog is a knowledge management system that provides information about IT services to both customers and service providers [1]. The IT service catalog lists all services which the IT service provider currently offers. In contrast to the IT service portfolio, the IT service catalog is visible to the customer. As the IT service catalog is a knowledge management system, the aspect of knowledge management is critical to the design of the catalog. Knowledge management describes the application of management techniques to optimize the relationship between data, information, and knowledge [2]. Knowledge management is a critical capability that firms require to increase maturity levels of IT service management [2]. IT departments transitioning from technology-focused to a service-centric strategy are, however, challenged by low knowledge management capabilities [3]. Firms often do not document data, information, and knowledge before implementing knowledge management systems such as the IT service catalog. Moreover, firms store IT service knowledge, information, and data on IT services in multiple sources.

A limited number of studies address the topic of IT service catalogs. Moreover, the literature on IT service catalogs is less consistent as the studies' research contributions are thematically scattered. Prior research on the topic of IT service catalog design suggests various specific IT service catalog examples and structures. However, little discussion exists about how companies can apply and implement those IT service catalog examples. As far as we know, no previous research has investigated what information content is necessary for which specific IT service catalog use case [4], [5]. Due to the lack of guiding methods, practitioners guides describe that the implementation of an IT service catalog can become an exasperating experience [3], [6].

Our research objective is to understand how we can scope the information content of IT service catalogs. This study explores the use of a user-centric design science method to define the scope of the information content of an IT service catalog for use in IT service management. By using the method, IT service catalog designers can take a firms' knowledge management capability into account when defining design requirements for IT service catalogs.

Section 2 introduces the IT service catalog further. Section 3 explains how IT service catalog designers can use a method based on design science to scope content and use of an IT service catalog. Section 3 also explains how we 
tested the method by conducting a case study during the IT service catalog design projects of 5 IT departments of a Danish transport and logistics company. Section 4 discusses our findings. Section 5 concludes.

\section{THE IT SERVICE CATALOG}

The IT service catalog is a knowledge management system that is central to IT service management [7]. The use of an IT service catalog as part of the IT service management intends to make IT service offerings explicit to the customer. The Information Technology Infrastructure Library defines the strategic objective of service catalogs as ensuring a shared IT service understanding between customer and service provider [1].

The following subsections describe the definition, structure, and content of IT service catalogs.

\section{A. Definition and Structure}

Following the definition from the Information Technology Infrastructure Library, an IT service catalog includes any live services [1]. An IT service catalog is a knowledge management system that provides information about IT services to both customers and service providers [1]. An IT service catalog is a communication tool: It transparently outlines the IT services offered to customers by describing the scope, characteristics, and costs of an IT service [3].

Regarding its structure, a service catalog is usually split into two views: The customer view and the technical view. The customer view provides information about the value of a specific IT service. Functionality, business process support, or business capability support are examples of attributes that express the value of IT services. The technical view explains the technical aspects of the IT service delivery including attributes of IT assets (e.g., software, hardware, database) and IT processes [8].

The Information Technology Library provides a generic IT service catalog example. However, the lack of implementation guidelines and customizable use cases for the IT service catalog limits the adoption of the generic IT service catalog structure in firms. The Information Technology Infrastructure Library does not provide a framework for the structuring of customized service catalogs.

\section{B. Content}

The best-practice IT service catalog includes information about the IT service offerings, technical IT service definition, explicit cost allocations, and service level agreements including capacity and availability levels [6]. ITIL says, however, that the firms shall define the IT services and associated terms of use for technical services individually [1].

The scope of the information contained in a service catalog is directly linked to resource consumption required for designing, building, running and supporting the IT service catalog during its lifecycle. The information content of the service catalog constrains how the service catalog integrates with other knowledge management systems, such as the IT portfolio or the configuration management database (CMDB) [1].

Over scaling the service catalog results in having content in the service catalog that the end-user does not require. Over the life-cycle, the IT service catalog would be unnecessarily expensive. Under-scaling the service catalog limits the use cases of the service catalog and potential of meeting the objective of the service catalog. Understanding how firms can scope the information content of IT service catalogs to reach the expected use case of the service catalog is therefore valuable for both practitioners and researchers.

In the following, a method will be proposed which considers such a contingency-approach to scoping the information content of IT service catalogs.

\section{RESEARCH METHOD}

This study describes how IT managers can use a design science method to scope the information content of the catalog in the early phase of the IT service catalog design process. In the following, we explain (1) why we use the design science research method, (2) how we conducted a case study to test the application of the method in industry, (3) how to use the proposed method systematically, (4) how we applied the method to generate our scientific findings on the design of service catalog use cases and content, and on the use of the proposed method.

\section{A. Suitability of the Design Science Approach}

Using a design science approach is justified because the research problem is a first step towards designing an IT service catalog which is an individually designed IT artifact [9]. The IT service catalog is an IT artifact as it is a tangible by-product of a software developing process [10]. Researchers and practitioners design IT artifacts to address an essential organizational problem [10]. When defining design requirements for IT artifacts, the results of applying the design science research methodology are justified problem statements, justified design objectives and refined research problems [11].

During design science research projects, the user of the IT artifact provides the primary input for answering the research questions. Due to the high user involvement in design science research, the proposed method aims to be especially suitable for use in IT departments with a low knowledge management capability and maturity in IT service management.

\section{B. Case Study}

Research on designing IT service catalogs, including published service catalog examples and practitioner's 
guides, did serve as rigor for this study. We used the existing theory about design science research methodology to apply this methodology to our research problem.

To investigate how IT managers can use design science research methods to scope IT service catalogs, we conducted a case study in industry. In total, ten experts and future users of the IT service catalog participated in semistructured interviews and workshops. The IT service catalog projects used as the basis for this study intended to describe the IT services out of IT applications used for transport planning and management. To evaluate the findings from the case study, we set evaluation criteria. We tested whether the users of the IT service catalog found the derived design requirements suitable and applicable for IT service catalog projects. We compared our findings with the literature and best-practice guides.

In the following subsection, we present the design science method systematically.

\section{Proposed Design Science Method}

In general, a design science research process includes the research activities (1) problem identification, (2) design, (3) implementation and (4) use [11]. This study investigated in detail the early phase of the design of the IT service catalog (problem identification) but did not observe the entire design science research process.

Following the design science research methodology used in information systems research [12], we started with (1) identifying a relevant problem, (2) evaluating of the initial problem statement, (3) deriving design requirements and (4) evaluating of design requirements.

Our proposed method included a build - ex-ante evaluation concept described by Sonnenberg and Brocke to evaluate the design objectives and findings [11]. The use of these concepts forced the IT service catalog designers to include rigorous evaluations during the design process. In this study, we used two evaluations: Evaluation 1 validated the initial problem statement, and Evaluation 2 evaluated the design objectives. The entire process, including the inputs and outputs for the evaluation steps, is displayed in Fig.1.

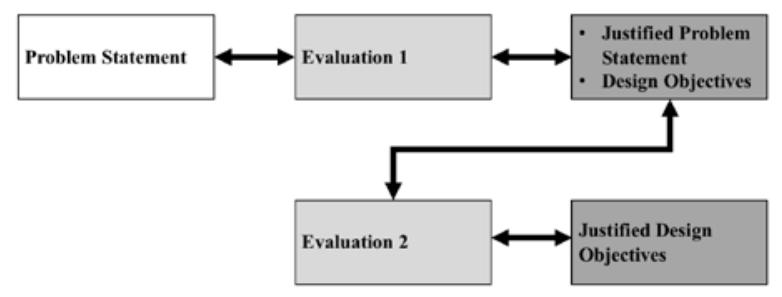

Fig 1. Builtex-ante evaluation process

In the following subsections, we explain further how we applied the proposed method to the context of the IT service catalog design.

\section{Problem Statement and Evaluation 1}

In this study, the practical problem of how to design a suitable IT service catalog for the use in IT service management was the input for the design process. During Evaluation 1, we derived design objectives for the service catalog information content, and we justified the initial problem statement and expected use cases of the service catalog. To evaluate the initial problem statement of not having an IT service catalog implemented to support IT service management, we conducted semi-structured interviews with six executive IT managers. The evaluation criteria were suitability and applicability of the information contained in an IT service catalog to the use cases of IT service catalog. During the interviews, we asked the participants to define the

- Problem of not having a service catalog,

- Expectations on a service catalog,

- Use cases of a service catalog, and

- Information contents.

We consolidated and analyzed the interview results. The results were compared with best practice guides and theory to justify the initial problem statement. We tested if an IT service catalog following the ITIL standards could solve the initial problem and matched the expected use cases of an IT service catalog. We derived the design objectives for the service catalog from the information content requirements of the consolidated expert interviews.

\section{E. Design Objectives and Evaluation 2}

During Evaluation 2, we tested all derived design objectives from Evaluation 1. Additionally, we further defined the scope of the information content of the service catalog. Therefore, we conducted ten expert interviews with the future users and stakeholders of the service catalog. To improve the validity of our result, we increased the number of participants in Evaluation 2 compared to Evaluation 1. The participant group of Evaluation 2 included additional service catalog users with competencies in IT service management, IT operations, and IT governance. The evaluation criteria are suitability and applicability of the information content contained in an IT service catalog to the use cases of IT service catalog.

\section{RESULTS}

\section{A. Refined Design Problem: Use Cases for a Service Catalog}

Table 1 shows the use cases of an IT service catalog that we have identified during Evaluation 1. The results are sorted in descending order of relevance. Table 1 also states information content requirements for the respective use case. Evaluation 2 further tested those information content requirements. 
TABLE I

JUSTIFIED USE CASES AND INFORMATION CONTENT OF THE IT SERVICE CATALOG

\begin{tabular}{|c|c|c|}
\hline Priority & Use Cases & Information Content \\
\hline \multirow[t]{3}{*}{1} & \multirow[t]{3}{*}{$\begin{array}{l}\text { The value proposition } \\
\text { of the IT service }\end{array}$} & $\begin{array}{l}\text { The functionality of technical } \\
\text { IT service }\end{array}$ \\
\hline & & $\begin{array}{l}\text { Business capability enabled } \\
\text { by the IT service }\end{array}$ \\
\hline & & Business process support \\
\hline \multirow[t]{3}{*}{1} & \multirow{3}{*}{$\begin{array}{l}\text { Transparency of the IT } \\
\text { service cost structure }\end{array}$} & The total cost of IT service \\
\hline & & $\begin{array}{l}\text { Cost allocation to technical } \\
\text { assets and processes }\end{array}$ \\
\hline & & $\begin{array}{l}\text { Cost allocation to IT service } \\
\text { management processes }\end{array}$ \\
\hline \multirow[t]{2}{*}{3} & \multirow{2}{*}{$\begin{array}{l}\text { Define and display } \\
\text { service level agreements } \\
\text { (SLA) and operating } \\
\text { level agreements (OLA) }\end{array}$} & $\begin{array}{l}\begin{array}{l}\text { Interdependencies } \\
\text { services }\end{array}\end{array}$ \\
\hline & & $\begin{array}{l}\text { The opportunity of varying IT } \\
\text { support processes }\end{array}$ \\
\hline 4 & $\begin{array}{l}\text { Standardized IT service } \\
\text { language }\end{array}$ & $\begin{array}{l}\text { Standardized use of IT service } \\
\text { terms and definitions }\end{array}$ \\
\hline \multirow[t]{2}{*}{5} & \multirow{2}{*}{$\begin{array}{l}\text { Automated service } \\
\text { orderings and service } \\
\text { requests }\end{array}$} & $\begin{array}{lll}\text { Defined service ordering } \\
\text { processes }\end{array}$ \\
\hline & & $\begin{array}{l}\text { Integration to a self-service } \\
\text { portal }\end{array}$ \\
\hline 6 & $\begin{array}{l}\text { Support for IT } \\
\text { processes: Disaster } \\
\text { management, capacity } \\
\text { management, change } \\
\text { management }\end{array}$ & $\begin{array}{l}\text { Defined IT service support } \\
\text { processes }\end{array}$ \\
\hline
\end{tabular}

Whereas the first four use cases are well aligned with the use cases found in practitioner's guides and ITIL, the last two use cases have not been mentioned in the IT service catalog literature before. The nonalignment of the use cases mentioned in theory and practice shows that the users of the service catalog had different expectations on the service catalog. A catalog designed following the example of existing service catalog models thus won't fulfill the stated needs on an IT service catalog.

Conducting the design science method for deriving requirements on the expectations of the service catalog led to identifying service catalog use cases which add to the design and understanding of best-practice IT service catalogs. Making the non-alignment between user expectations and the traditional objectives of the service catalog explicit is one indicator of the validity of this approach.

\section{B. Refined Design Objectives: Content of the Service Catalog}

As it is shown in Table 1, the IT service catalog should describe (1) how the IT service provides value to the customer/business, (2) the cost of the IT service, (3) the service and operating levels of the IT service, and (4) the processes required to build, support and run an IT service.

Table 2 shows the justified information content of the technical view of the service catalog. The study participants came up with a more detailed description of the technical information content of the service catalog than ITIL.
Delivering refined design requirements is one indicator of the validity of this approach. Whereas the technical information content shown in Table 2 is more detailed than the ITIL description, the study participants did not consider some information that is usually displayed in the technical service catalog as relevant. In particular, the study participants did not consider the operating level agreements (OLAs) which define the service level of the technical IT services as relevant. Even though displaying service level agreements and operating level agreements was one of the highest ranked use cases amongst the users of the service catalog, the user found that providing the specific information content needed to define SLA and OLA was too extensive for the first service catalog design. This change of priority is an example of how the aspect of a low knowledge management capability impacts information content determinations in practice and validates the contingency-considerations to IT service catalog information content scoping.

\section{Refined Research Problem: Importance of the IT Service Definition}

The five use cases with the highest priorities (exact IT service value, cost transparency, SLA and OLA, standardized IT service language, automated service orderings) and the scope of information highly depend on how IT departments define IT services.

During the interviews, the experts mentioned different views of what an IT service is. The experts' discrepancy in the understanding of how an IT service is defined shows that the IT service definition is an essential prerequisite for defining the scope of an IT service catalog.

ITIL defines an IT service as 'a value that is based on the use of information technology to support the business processes of the customers [1].' The academic literature describes IT services mainly from a technical or marketing perspective.

TABLE II

JUSTIFIED TECHNICAL INFORMATION CONTENT OF THE SERVICE CATALOG

\begin{tabular}{|l|cl|}
\hline \multicolumn{1}{|c|}{ Category } & & Justified Information Content \\
\hline $\begin{array}{l}\text { Technical IT } \\
\text { services }\end{array}$ & $\bullet$ & $\begin{array}{l}\text { Application service } \\
\text { Server service }\end{array}$ \\
& $\bullet$ & $\begin{array}{l}\text { Data service } \\
\text { Middleware service }\end{array}$ \\
\hline $\begin{array}{l}\text { The } \\
\text { functionality of } \\
\text { technical IT } \\
\text { service }\end{array}$ & $\bullet$ & $\begin{array}{l}\text { Components: Logical and physical } \\
\text { assets that constitute the above- } \\
\text { mentioned technical IT services } \\
\text { Processes: Processes required to run } \\
\text { and support the above mentioned } \\
\text { technical services during the lifecycle } \\
\text { of an IT service }\end{array}$ \\
\hline $\begin{array}{l}\text { Cost of } \\
\text { technical IT } \\
\text { services }\end{array}$ & $\begin{array}{l}\text { Direct cost } \\
\text { The indirect cost of a technical IT } \\
\text { service }\end{array}$ \\
\hline
\end{tabular}


For instance, practitioners and researchers are using the term IT service for e-service offerings, service-products, service processes, software applications and hardware configurations, or support request processes [13].

However, it is not ultimately clear how complex IT services can be structured and described by choosing suitable attributes to support IT service management. It is therefore still a challenge to define and model IT services for the practical use in an IT service management context aiming to support the optimization of IT service delivery.

Besides the lack of clarity in the IT service definition, other knowledge management implications in the IT service catalog project challenged the experts. In this case study, the experts had to find solutions for the

- $\quad$ Lack of explicitly defined IT service offerings

- A high number of IT services offerings

- A high number of IT service variant offerings

- A high number of non-standardized IT service offerings.

\section{Evaluation of the Proposed Method}

To evaluate the method mentioned above, we tested the aspect of suitability and applicability of the method to the problem. The use of the method applied to the case study led to a justified problem statement, justified design objectives and refined research problems related to the IT service catalog. The case study results confirmed that knowledge management capability indeed impacts the information content scoping of IT service catalogs. By using the method, we considered knowledge management implications when defining the information content and the information content kept fit to the expected use case of the IT service catalog. As the proposed method uses built-in evaluations, the outcomes of the method were immediately evaluated. It is, therefore, valid to say that the method can serve as a suitable pre-feasibility method to determine the information content of IT service catalogs.

\section{CONCLUSION}

This study proposes a design science-based method to derive requirements on the information content of an IT service catalog. Testing the method led to a refined problem statement and justified design objectives which led to a proactive and successful scope reduction of the information content of the IT service catalog.

Our results furthermore stated the relevance of having the scope of an IT service catalog defined rigorously.

We propose to test the method during other IT service catalog implementation projects to generalize the method. We expect to test the method during the process of defining the service catalog layout, structure or requirements for a service catalog software tool.

To further research the use of an IT service catalog in IT service management, we propose to design the IT service catalog together with industrial case companies.
The next steps could be to investigate how (1) to design and implement a service catalog construct and populating the service catalog with different IT services, (2) to use the service catalog, and (3) to evaluate all design activities.

\section{REFERENCES}

[1] L. Hunnebeck, C. Rudd, and S. Lacy, "ITIL Service Design,” TSO, London, 2011.

[2] C. Thornley, M. Carcary, N. Connolly, M. O’Duffy, and J. Pierce, "Developing a Maturity Model for Knowledge Management (KM) in the Digital age,” Eur. Conf. Knowl. Manag., no. September, p. 874, 2016.

[3] W. T. Dumoulin, B. Fine, and R. Flores, Defining IT Success Through The Service Catalog. Van Haren, 2007.

[4] V. Nissen, D. Jung, M. Petsch, and C.-P. Präg, "Recommendations for a general IT Service Catalogue structure,” Enterp. Model. Inf. Syst. Archit., vol. 10, no. 1, pp. 89-108, 2015.

[5] M. Arcilla, J. A. Calvo-manzano, and T. San, "Building an IT service catalog in a small company as the main input for the IT financial management,” Comput. Stand. Interfaces, vol. 36, pp. 42-53, 2013.

[6] M. O’Loughlin, The Service Catalog. Van Haren, 2010.

[7] SS OGC v3, Service Strategy. London: TSO, 2007.

[8] F. Nord, R. Dörbecker, and T. Böhmann, "Structure, Content and Use of IT Service Catalogs - Empirical Analysis and Development of a Maturity Model,” in Proceedings of the Annual Hawaii International Conference on System Sciences, 2016, vol. 2016-March, pp. 1642-1651.

[9] S. T. March and G. F. Smith, "Design and natural science research on information technology,” vol. 15, pp. 251-266, 1995.

[10] B. A. R. Hevner, S. T. March, J. Park, and S. Ram, "Design Science In Information Systems Research,” MIS Q., vol. 28, no. 1, pp. 75-105, 2004.

[11] C. Sonnenberg and J. Brocke, "Reconsidering the BuildEvaluate Pattern in Design Science Research,” in International Conference on Design Science Research in Information Systems, 2012, pp. 381-397.

[12] K. Peffers, T. Tuunanen, M. A. Rothenberger, and S. Chatterjee, “A Design Science Research Methodology for Information Systems Research,” J. Manag. Inf. Syst., vol. 24, no. 3, pp. 45-77, 2007.

[13] J. Cardoso and S. Nickel, Fundamentals of Service Systems. Springer, 2015 